\title{
Development and Complex Dynamics at School Environment
}

\author{
Miguel Angel Fuentes $\mathbb{D}^{1},{ }^{1,2,3}$ Juan Pablo Cárdenas, ${ }^{4}$ Natalia Carro, ${ }^{5}$ and Mariana Lozada ${ }^{5,6}$ \\ ${ }^{1}$ Santa Fe Institute, 1399 Hyde Park Road, Santa Fe, NM 87501, USA \\ ${ }^{2}$ IIF-Sadaf/CONICET, Bulnes 642, Buenos Aires 1428, Argentina \\ ${ }^{3}$ Facultad de Ingeniería y Tecnología, Universidad San Sebastián, Bellavista 7, Santiago 8420524, Chile \\ ${ }^{4}$ Net-Works, Angamos 451, Viña del Mar, Chile \\ ${ }^{5}$ Instituto de Investigaciones en Biodiversidad y Medioambiente, CONICET, 8400 Bariloche, Argentina \\ ${ }^{6}$ Laboratorio Ecotono, Universidad Nacional del Comahue, 8400 Bariloche, Argentina \\ Correspondence should be addressed to Miguel Angel Fuentes; fuentesm@santafe.edu
}

Received 28 April 2018; Accepted 5 November 2018; Published 2 December 2018

Guest Editor: Chen Yu

Copyright ( 2018 Miguel Angel Fuentes et al. This is an open access article distributed under the Creative Commons Attribution License, which permits unrestricted use, distribution, and reproduction in any medium, provided the original work is properly cited.

In this work we use complex systems methodologies to analyze quantitatively the impact of an intervention involving cooperative and self-awareness activities on social interactions in children. The aim of this study is to evaluate behavioral plasticity of social relationships between peers in 6-7 year-olds who participated in the intervention conducted in a school context. The intervention consisted of 8 one-hour long sessions comprising mindfulness-based practices, collaborative activities that required cooperation, and perspective-taking instances in which children shared feelings, perceptions, and needs felt during the activities. We used complex network and game theory to evaluate pre-post-intervention variations. Social relationship was analyzed with a sociogram in both the intervention group and a control group which continued with regular classes. By means of the sociometric questionnaire we asked each child to mention which classmates he/she would choose as playmates and which he/she would not. Changes in the number of peers selected and rejected reflected changes in the pattern of social relationships pre-post-intervention. Our findings show that participating in the intervention positively modulated social interactions since we found an increase in the diversity and quality of positive links and a reduction in negative ones; a higher level of integration, indicated by enhanced positive networks where children with many positive connections tended to connect with those with few links; and more positive interactions between genders. These findings were not observed in the control group. Through the use of the mentioned methodologies, the current investigation provides new quantitative evidence of social network plasticity in children, an important topic which, to our knowledge, has been little studied. Results from this work indicate that positive transformations in social relationships can be fostered through the performance of this kind of intervention.

\section{Introduction}

It is increasingly clear that social and individual dynamics, as for example in children, involve complex interactions embedded in networks, where information flow creating emergent properties that can be studied using different quantitative techniques, as nonlinear science, network analysis, information theory, etc. [1]. Behavioral plasticity in terms of prosocial attitudes, i.e., changes in prosocial behavior that result from experience, has been recently demonstrated in young children (e.g., [2-4], Lozada, 2014; [5-7]). Several investigations showed that children display a great ability to modulate their behavior when they experience situations involving empathic concern, caring for others, cooperative activities, etc. In particular, emotional resonance between self and other enables the emergence of empathic concern $[8,9]$, which has been defined as the affective response related to the understanding of another's emotional state [10] and is a necessary condition for prosocial attitudes [11-15]. Interestingly, it has been observed that behavioral changes associated with prosocialness, positive social relationships, and emotional regulation are also accompanied by favorable effects on physical and psychological well-being (e.g., [3, 6]). Numerous investigations have shown that empathic 
concern for others and social network diversity can foster healthy states ([16-19], Pace et al. 2010, 2012; [20]). It has been proposed that social relationships protect physical health and well-being (e.g., [21-23]). Several researchers have demonstrated a relationship between social network size and diversity (social network structure) and the functioning of the immune system $[24,25]$ and HPA axis activity (e.g., [2628]). Supportive social networks and positive relationships can act as a buffer against the potential negative effects of stressful events (e.g., [29, 30]). Growing evidence emphasizes the role of peers as buffers against stress in children [3133]. Consistent with this, it has been found that altruism in human beings, which involves behaviors such as helping, sharing, comforting, and informing, tends to occur beyond reciprocity, kinship, or reputation in a higher proportion than predicted by evolutionary theory $[34,35]$. This highlights the relevance of prosociality in human beings, suggesting that consideration for others can confer benefits not only on the receiver but also on the giver. In line with this, altruistic motivation has been shown to emerge at an early age; it has been observed that 18-month-old children spontaneously help nonfamiliar individuals [36, 37] and show empathic concern for those in distress $[38,39]$. Interestingly, it has been found that children of less than 2 years of age exhibit greater happiness when sharing with others than when receiving treats themselves [40], and that babies of 3 to 10 months prefer helping situations to neutral or hindering ones [41, 42]. The above-mentioned investigations reveal the early emergence of prosocial attitudes and confirm their beneficial effects.

It has been proposed that social cognition is inseparable from processes of interaction with others (e.g., [43-45]). That is, cognitive agents are not passive data collectors who model the world, but active participants who enact a world in close connection with others (e.g., [44-46]). Therefore, social cognition involves not only understanding others but also understanding with others [45, 47]. Behavioral plasticity related to social interactions in children has been analyzed by the application of activities, which seek to promote relationship changes in controlled situations (e.g., [48]). Thus, observable changes are evaluated and compared before and after participation in a specific intervention. In earlier work with 6- to 7-year-old children we found that interventions involving mindful and cooperative activities, which favored self-connectedness and connectedness with others, enhanced generosity between peers [49]. Therefore, altruistic attitudes under anonymous conditions increased after the intervention. Similarly, when this type of intervention was performed in 7 to 9 year-olds, social relationships between peers improved and stress levels also decreased [48]. Other recent investigations showed that mindfulnessbased interventions in preschool children fostered good health and social-emotional development [3]. In addition, other programs of activities involving self-awareness practices and caring for others (e.g., cognitive-based compassion training) favored prosociality, stress reduction (e.g., [6]), empathic concern, compassionate attitudes [5], and emotional regulation ([50], Flook et al., 2010; [51, 52]). Moreover, cooperative play increased self-confidence, prosocialness, and self-regulation in participants $[53,54]$. These studies illustrate how mindfulness-based practices and cooperative experiences can promote prosocial behavior and well-being in children, highlighting the plasticity displayed at this early age.

Little is known about how behavioral interventions have the potential to change peer relationship networks in the sense of increasing socialization. However, while some studies have analyzed intervention effectiveness in improving peer relationships in children (e.g., [55]), few have proposed the theoretical-methodological approach of social network analysis to assess their effects (e.g., $[56,57]$ ). It has been proposed that social network analysis could improve ways of testing the effects of behavioral interventions by considering interdependencies of peers network data instead of taking into account aggregation of individual characteristics (e.g., [57]). Social relationships in a group can be evaluated through the sociogram, a sociometric parameter which depicts the dynamics of social processes [54, 58, 59]. This trustworthy tool describes the social network of each child in a group, assessed by means of a questionnaire asking each child to say which peers they want to play with, and which they do not. When applying this measure in diverse instances within a certain group, the dynamics of social interactions can be assessed. Since this measure also identifies antagonistic interactions within a group, social exclusion and social integration can be recognized. Consequently, this measure illustrates social links within a group of peers, contributing to our understanding of the complexity and dynamic nature of children's social networks.

In the present work, via a case of study, we aim to further study the impact of experiences, which involve mindfulnessbased practices and cooperative activities, which increase awareness of themselves and of others, on social interactions in 6-7 year-olds. Considering the beneficial effects of prosocial behavior, along with the behavioral malleability of this age, we evaluate social network plasticity in a formal education context. We carry out a short intervention, which consisted of 8 one hour long sessions comprising: mindfulness-based practices, collaborative activities, and perspective-taking instances that has previously proven to favor prosocialness between peers of this age (see, for example, [49]). Social network configuration is compared before and after the intervention in both an experimental and a control group. We expect to find that participation in the intervention will bring about an increase in the quality and diversity of positive social relationships between peers and a decrease in the negative ones. These potential favorable changes in the network configuration could support the implementation of this kind of intervention in educational settings which might improve social dynamics in children.

\section{Methodology and Methods}

2.1. Participants. This research was carried out with children aged 6-7 in a public school. All participants were all in good health, and there were no significant differences in body mass index or socioeconomic level. One class was selected at random as the experimental group, which included 24 participants (62.5\% boys and $37.5 \%$ girls), and another class 
of 20 children ( $45 \%$ boys and $55 \%$ girls) formed the control group (which followed the regular school program). In the experimental group three researchers performed the intervention once a week, accompanied by the class teacher. The study was performed in accordance with the Helsinki Declaration, and all procedures were conducted with the written consent of parents and school authorities. The data collected were treated under confidential conditions.

We first interviewed each child individually to evaluate the sociometric parameter (see below). We then performed an intervention program once a week for 10 weeks, during which children carried out self-awareness practices and cooperative play and shared a moment of reflection. On conclusion, we conducted a postintervention individual interview, with the same content as the first.

By means of a sociometric questionnaire $[54,59]$ we evaluated social connectedness previous to and after the intervention in both experimental and control groups. In the individual interviews, children were asked to say which peers they would like to play with and which they would not like to play with. That is, children's answers referred to the name of peers selected or rejected to play with (in order to determine positive versus negative interaction links, respectively).

2.2. Intervention. The program consisted of sessions of $60 \mathrm{~min}$ each. Each one included three consecutive instances: an initial stage of self-awareness practices, a second stage of cooperative games, and a third stage of group reflection (as in $[48,49]$ ). The first instance included breathing techniques and other mindfulness practices and exercises that involved slow, deliberate movements that children could focus on for several minutes. These practices helped children become more aware of moment-by-moment experiences. The cooperative games entailed playing in a collaborative way in order to achieve group goals, as conducted in Garaigordobil [54]. In the final instance, the children were invited to sit in a circle, and each child had the opportunity to express how they felt, say which parts of the game they enjoyed most and whether they preferred helping or being helped.

2.3. Social Network Analysis. We evaluated children's networks comparing the pre- and postintervention sociograms. Children's networks are represented by graphs $G(C, E)$ projected from the sociograms, where $C$ is the set of children in the class and $E$ the set of links between them. These links can be positive or negative, depending on the interaction between the children. We performed a detailed network analysis at different levels. At macrolevel, we computing metrics such as the average connectivity of children, their in-degree and out-degree (i.e., number of links arriving at a node and the number of links that leave a node, respectively), the density of the networks (i.e., proportion of existing links in relation to possible links), and their community structure (i.e., set of nodes that are more connected among themselves than with the rest of the network), using the algorithm proposed by Blondel, Guillaume, Lambiotte, and Lefebvre [60]. At mesolevel, we compute the correlation connectivity between children, using the degree assortativity, $r$, as the measure that captures these correlations [61]. At microlevel, we studied the triad configurations. According to Kadushin [62], the triad is one of the most important motif classes in social networks, since they represent the beginnings of a "society" that is independent of the links between dyads. The role of the children in these networks was also analyzed.

\section{Results}

3.1. Macroanalysis. We constructed negative and positive networks, $\mathrm{NN}$ and $\mathrm{PN}$, respectively, for the control and experimental groups. NNs contain only links from a child (the source) who does not want to play with another (the target). In contrast, PNs are networks with links from children that want to play with other children. For both kinds of network we constructed two temporal graphs: one corresponding to the results of the first interview (preintervention measure) and the other to the second (postintervention measure).

Figure 1 shows the analysis of NNs and PNs before and after the intervention in both groups. The figure is divided into two: NNs at the left and PNs at the right. In both parts, again, two sections are plotted: the control group (left) and the experimental group (right). For each group we plot the parameter before and after the intervention. We observed that, in the case of average connectivity, $\widehat{k}$, in NNs, the number of negative links was higher (15.56\%) in the control group in the second measure than in the first, with a mean of 2.250 and 2.600, respectively. However, in the case of the experimental group, this number was lower (39.34\%) after the intervention than before, with a mean of 1.542 and 2.542, respectively. In the case of PNs, we observed that positive links increased in both groups but in the experimental group this increment was more marked $(24.10 \%)$, with a mean of 10.375 and 12.875 before and after the intervention, respectively, in comparison with the control group (8.18\%), whose means were 7.950 in the first measure and 8.600 in the second measure. The statistical analysis comparing the average indegree before and after the intervention showed a significant increase in PNs $(t=-2.66, p=.014)$ and a significant decrease in NNs $(t=-2.326, p=.029)$ in the experimental group, whereas in the control group no significant differences were found between the first and second measure for either PNs $(t$ $=-.804, p=.432)$ or NNs $(t=-.464, p=.648)$. The average outdegree before and after the intervention showed a significant increase in PNs $(t=-4.678, p<.001)$ and a significant decrease in NNs $(t=3.464, p=.002)$ in the experimental group. In contrast, in the control group, nonsignificant differences were found in PNs $(t=-1.51, p=.14)$ and NNs significantly increased $(t=-2.101, p=.049)$.

A similar pattern was found for network density. The NNs of the control group were more "populated" with negative links in the second measure (density index increased from .118 to .137) whereas the opposite occurred in the NNs of the experimental group (density index decreased from .111 to .067). In contrast, in the PNs scenario, the population of positive links increased more notably in the experimental group (density index increased from .458 to .560) than in the control group (density index only changed from .418 to .453).

The community structure shows that the control group in the NN scenario decreases between the first and second 


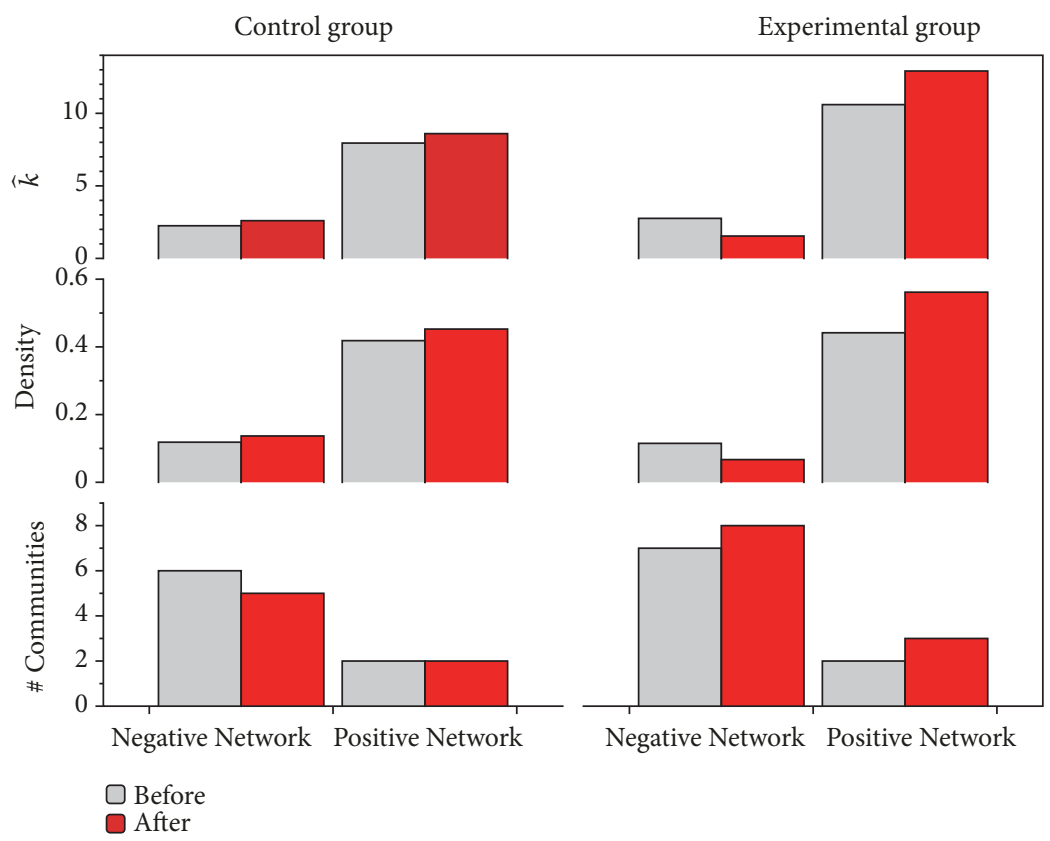

FIGURE 1: Network topological properties. Average network degree $\widehat{k}$ (top), link density (mid), and number of communities (bottom), for control and experimental groups for negative (left) and positive networks (right).

measures. This means that, in the second measure, the negative links are less confined than before. The opposite occurs in the experimental group where negative links seem to be more confined in communities (more communities). It is important to note that the students maintained, on average, $71.8 \%$ of their positive relationships after the intervention. Also, $75 \%$ of the students with less positive relationships (than the average) before the intervention increased their positive preferences to $93.5 \%$ after the intervention. Only $28.5 \%$ of those students with more positive relationships before the intervention increased the number of their relationships, and they did it on average only by $16.4 \%$. Obviously, the probability of choosing new positive relationships is lower in this latter group. The remaining $71.4 \%$ of this group maintained or decreased the number of positive relationships, although in an insignificant way. In the PN scenario, the number of communities increases in the experimental group, suggesting that the network of positive links presents a modular structure. The control group shows a similar tendency but to a lesser extent.

3.2. Connectivity Correlation Analysis. We also developed an analysis of the correlation between children's connections using the assortativity index, $r$, which is a measure that captures the correlation between node properties [61]. Thus, in the scenario of symmetric connection (undirected network), if densely/poorly connected nodes are connected to other nodes with many/few connections, the network is considered assortative, $r>0$. On the other hand, if densely/poorly connected nodes are connected with poorly/densely connected ones, the network is disassortative, $r<0$. If no correlation is observed, $r \sim 0$, nodes do not have a link preference. In the asymmetric connection scenario (directed networks)

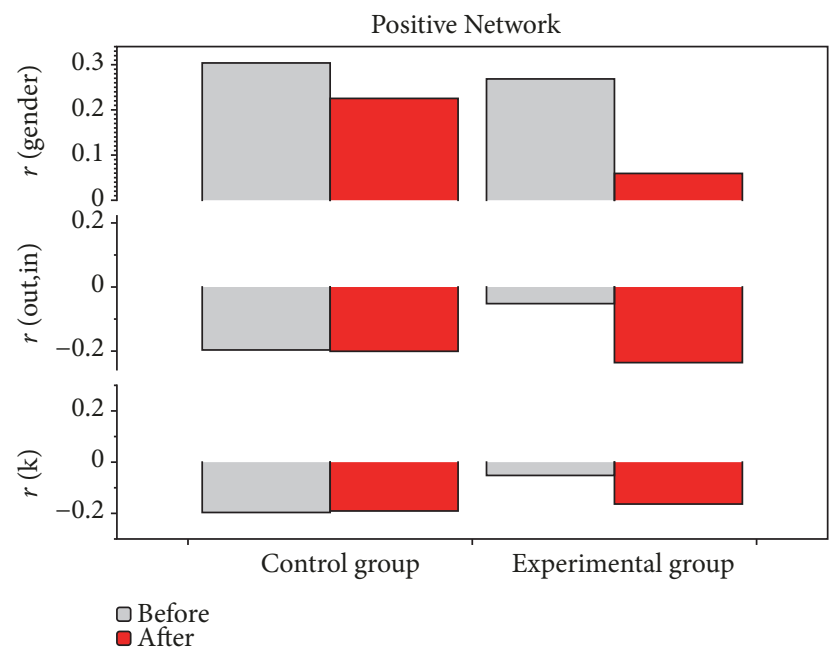

FIgURE 2: PN assortativity measure. $r$ (gender) (top), $r$ (out,in) (mid), and $r(k)$ (bottom) for control group (left) and experimental group (right).

all types of assortativity can be computed for PNs and NNs: $r$ (in,in), $r$ (out,in), $r$ (in,out), and $r$ (out,out) where the first element in the parentheses indicates the degree of the source node, and the second, the degree of the target node. We also performed correlation analysis by gender link preference.

No clear results were obtained for correlations in NNs, but we found some changes in the assortativity for PNs after the intervention (Figure 2). In the case of gender correlation we observed that, in the case of the control group, boys choose boys and girls choose girls; the correlation is positive $(r>0)$ before and after. However, in the experimental group 


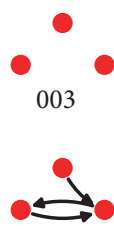

$111 \mathrm{D}$
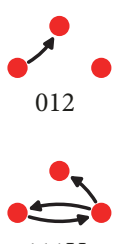

$111 \mathrm{U}$

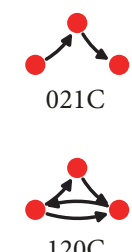

$120 \mathrm{C}$
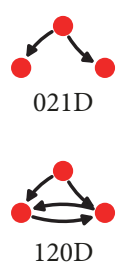

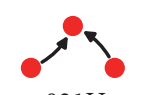

$021 \mathrm{U}$

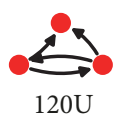

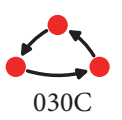

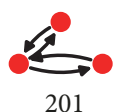

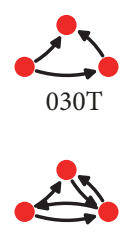

210
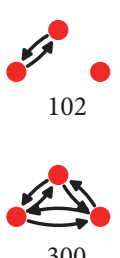

300

FIgURE 3: Triad configurations. 16 possible configurations of links between three nodes in a directed network.

gender correlation tends to disappear after the intervention (Figure 2, top).

The effect of the intervention on integration can also be observed in the correlation analysis for directed networks. In the case of $r$ (out,in) we can observe that no change occurred in the control group after the intervention; the PN of the control group remained disassortative. However, the $\mathrm{PN}$ of the experimental group changed from uncorrelated to disassortative, suggesting the integration of children with few positive choices (Figure 2, mid).

Finally, in the case of the degree assortativity $r(\widehat{k})$ for the control group, it can be seen that no change was observed at the second measure. However, in the case of the experimental group after the intervention, the PN were clearly disassortative; the correlation was observed; i.e., children with many/few positive connections tended to connect with those with few/many links (Figure 2, bottom).

3.3. Network Motif Analysis. Considering the direction of edges, we can also explain the structure of the networks on a local scale (child to child). In particular, we are interested in motifs as local connection patterns such as functional units like feed-forward and feedback loops. As an example, we carried out our analysis looking for variation in the frequency of four specific triad configurations for PNs and NNs. In PNs we searched for configurations 210 and 300 (the last two triads of Figure 3), whereas in NNs we focused on configurations 021U and 111D.

As can be seen in Figure 4 (left), negative triad configurations (021U and 111D) showed an increment in the case of the control group, whereas in the experimental group these configurations showed a significant decrease. In contrast, positive triad configurations 210 and 300 (Figure 4, right) showed a stronger increment in the case of the experimental group.

3.4. Microanalysis of Group Class Networks. Finally, we studied the effect of the intervention on the role of children in their class groups. Figure 5 shows two rows of networks: the bottom networks display the NN (left) and PN (right) of control group class before the intervention, while upper ones represent the structure of the networks after the intervention. Each one of the networks is drawn in a hierarchical way: the more frequently chosen children are located at the top of the networks, while to the right are those who choose more children. For example, in the case of the previous PN (bottom right), the node "Va" is highly chosen by the rest of the class (high in-degree) but this node also chooses many children (high out-degree), in comparison with "Ar" who chooses fewer children to play with (low out-degree). However, like "Va", "Ar" is also much chosen by the rest of the class (high in-degree).

It can be observed in the control group that negative leaders ("Am" and "Je") continue with the same characteristics in both PNs and NNs throughout the study (they are on the top of both NNs and on the bottom of the PNs). In this PN scenario, "Am" and "Je" are poorly chosen by the class; however, they choose many of their classmates (they are located to the right of the layout before and after, close to the center).

Something completely different was seen in the experimental group (Figure 6, same layout distribution as Figure 5). Even though before the intervention the $\mathrm{NN}$ is practically an inverted image of the $\mathrm{PN}$, as in the case of the control group where negative leaders are not positive leaders and vice versa, after the intervention the roles changed. New children appeared as negative and positive leaders, highlighting the effect of the intervention. Moreover, these leaders do not correspond to nonleaders on opposing networks as before. Finally, another effect of the intervention can be observed in the $\mathrm{NN}$ after the intervention. In this case, the nodes are concentrated on the left of the layout (i.e., they reject fewer than before).

\section{Discussion}

The methodologies used in this manuscript can be expanded in order to study other characteristics of human interaction in educational environment. The current study shows how self-awareness and cooperative activities enacted during an intervention increased positive social relationships between peers and diminished negative ones. Our findings suggest that the activities which involved working with others to attain shared goals positively modulated social interactions, highlighting the great behavioral plasticity of primary school children. Social network diversity and the quality of positive links improved after the intervention in the experimental group, whereas no such changes were observed in the control group. These outcomes were assessed by means of mathematical tools based on network theory, which made it possible to visualize the complexity and dynamics of children's social networks. The model showed that, after the intervention, positive interactions enhanced (more dense friendship networks and increase in positive triad configurations), positive interactions between children of different genders increased (weakening same-gender preference), and negative 

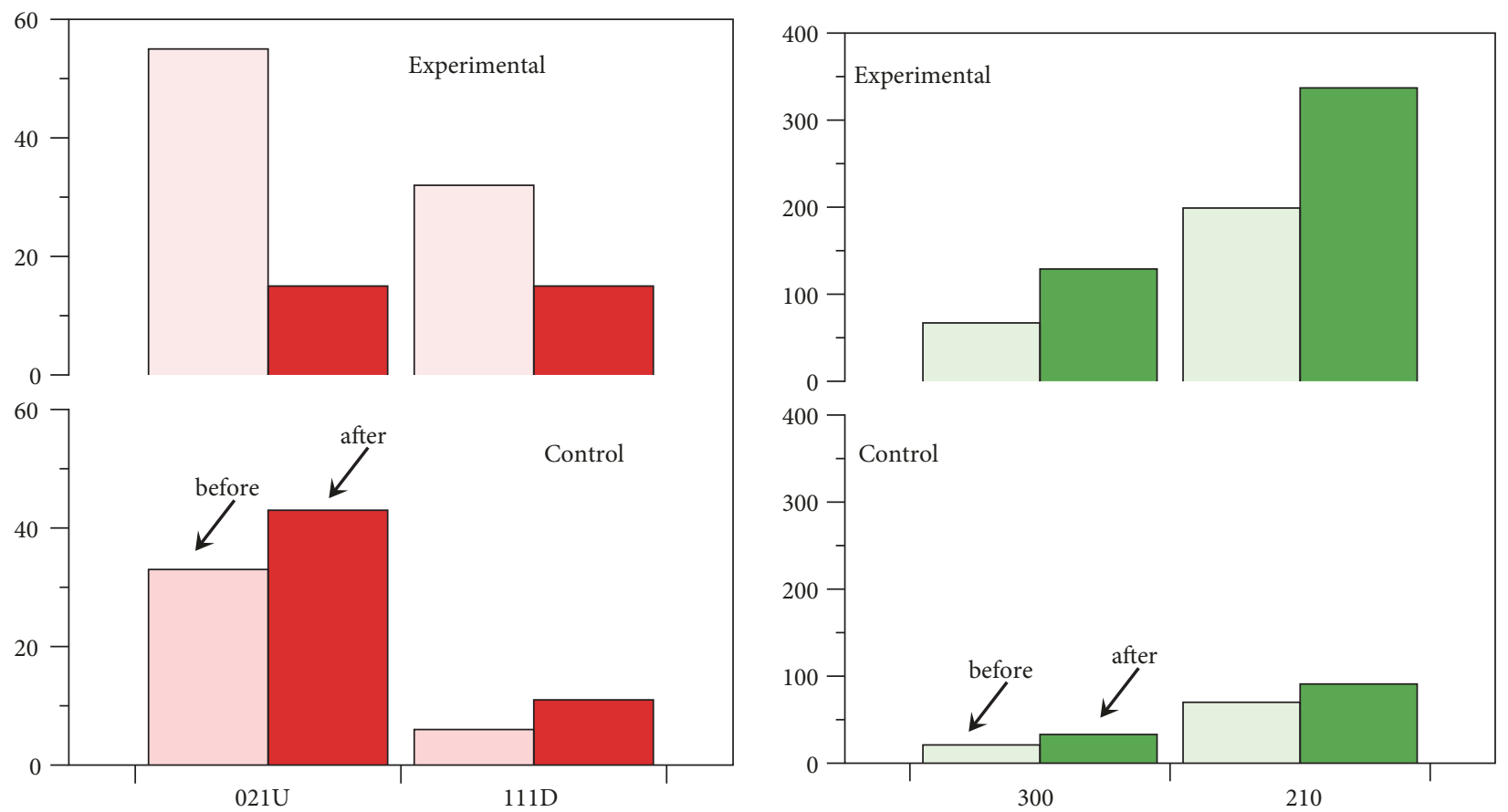

FIGURE 4: Variation in the number of triad configurations. Triads considered as negatives are shown in the left plot and positives on the right.
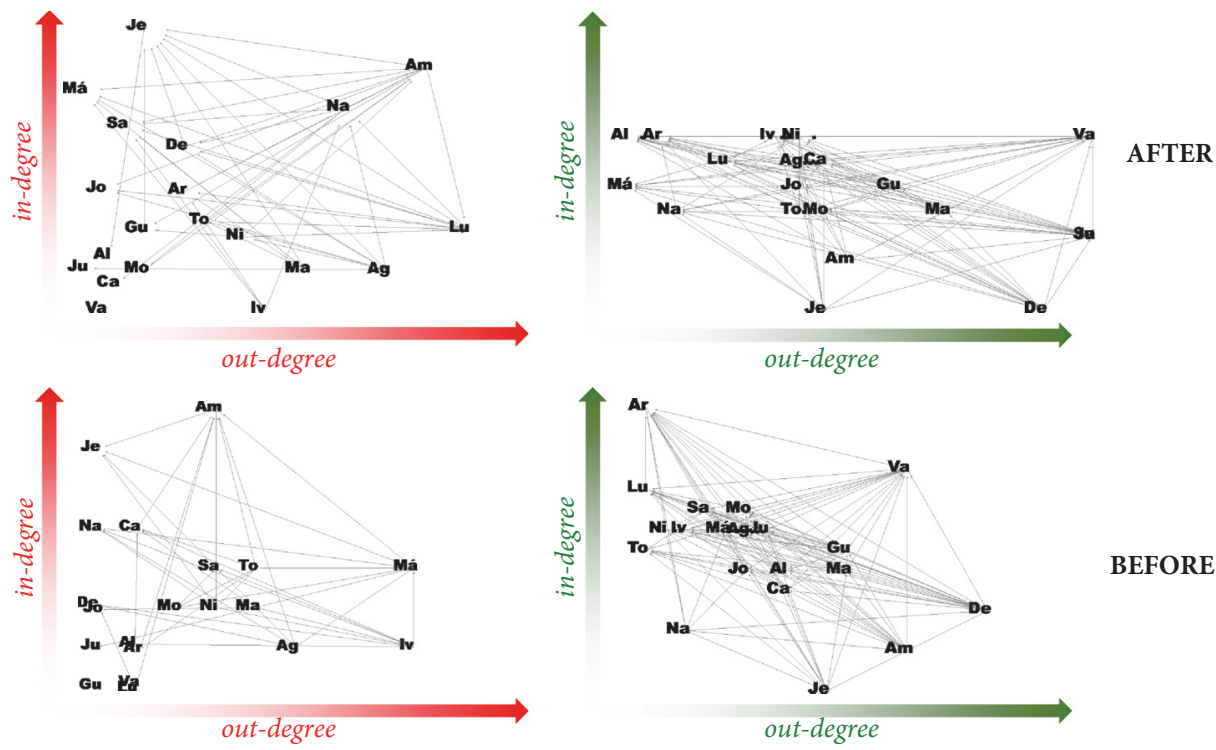

Figure 5: Control group networks. NNs (left) and PNs (right), in the first (bottom) and second evaluations (above). Network layouts show nodes which have a high number of in-degree connections located upper across the vertical axe and those with high number of out-degree connections located at the right of the horizontal axis.

interactions decreased (less dense enmity networks and decrease in negative triad configurations) and that children with many positive links connected with peers who had few links and vice versa. This may suggest the development of empathy on the part of the most frequently chosen children, allowing greater social integration. Likewise, both negative and positive networks were more confined within communities after the intervention, which could be indicating the emergence of a greater diversity of interactions between peers. In addition, the intervention allowed a roles' change in the group, given that new children appear as negative and positive leaders, that accounts their great plasticity.

The fact that this kind of intervention reduced negative interactions and increased positive ones agrees with previously reported findings suggesting that higher levels of social harmony can be promoted in schools. In addition, it has been found that this type of intervention can reduce stress levels (e.g., [48]), highlighting the significant impact 

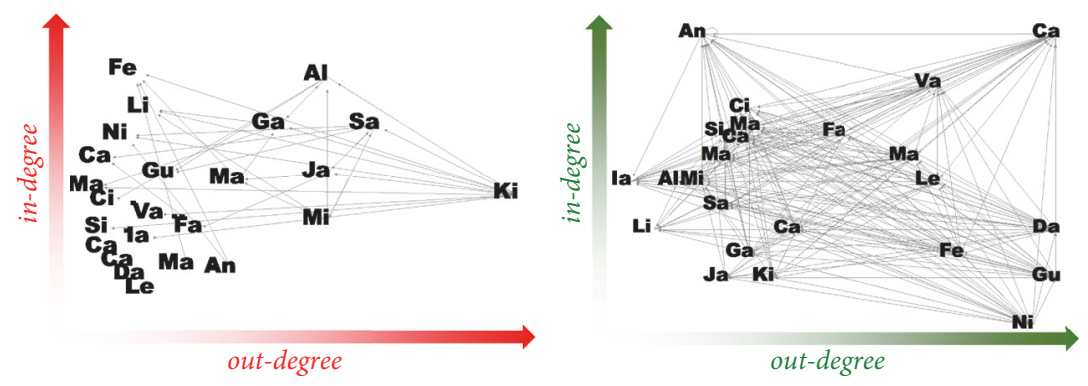

AFTER
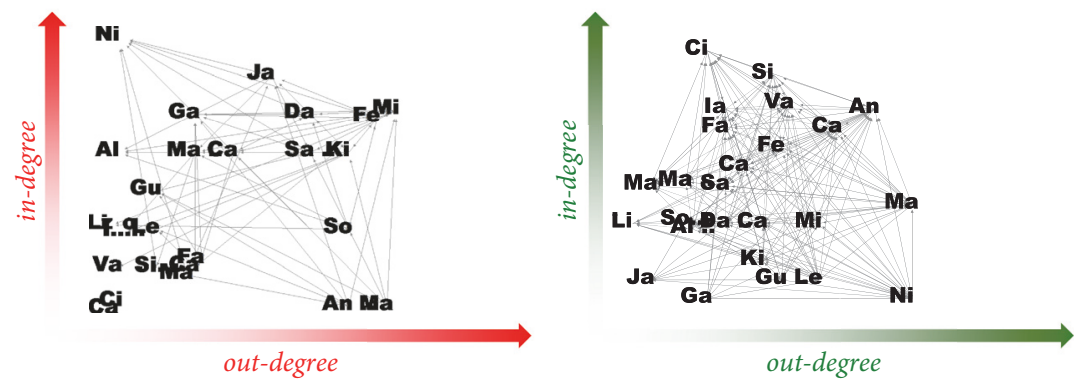

BEFORE

FiguRE 6: Experimental group networks. NNs (left) and PNs (right), before (bottom) and after (up) the intervention. Network layouts show those nodes with high number of in-degree connections located upper across the vertical axe and those with high number of out-degree connections located at the right of the horizontal axis.

of positive social networking and quality social relationships. These results further support the existence of the buffering effect of positive relationships, indicating the importance of implementing this kind of program during childhood. It is interesting to note that these findings are in accordance with recent work describing how children with lower stress levels show more highly developed social networks (high density of friendships) than children who suffer from chronic stress [63]. Moreover, our findings agree with previous investigations which also observed that social relationships were improved by cooperative play in children $[53,54]$ and that participation in a mindfulness-based prosocial training curriculum was able to promote self-regulation and prosocial behavior in young children $[3,6]$. While recent studies have evaluated the peer relationships of children using social network analysis (e.g., [63-66]), to the best of our knowledge, few studies have been carried out to evaluate changes in social dynamics after applying an intervention.

Interestingly, the activities carried out in the present investigation seem to have helped decrease self-centeredness in children, enabling them to connect with others and develop empathic concern, thus promoting higher richness of social diversity. This ties in well with the enactive theory which proposes that cognition emerges from participation and emphasizes the key role of participatory sense-making experiences, in which interaction plays more than a contextual role as it can promote social cognition [43, 45, 47].

Previous investigations have shown that empathy, which involves cognitive and emotional understanding of others, is related to emotional regulation [67] and the identification of others' situations, that enable the emergence of prosocial attitudes $[8,20]$. Other studies have shown that mindfulnessbased practices can contribute to the regulation of emotions as well as attentional focus (e.g., $[3,6,51,68-70]$ ).
The improvement of social relationships was accompanied by positive relational attitudes. For example, significant changes were observed during the reflective instance when children shared their appreciation of the experience and listened to others. We found that children were much more attentive to peers' verbal comments. In these perspectivetaking instances children could become aware of peers' perceptions, feelings, and needs, in addition to the selfperception of emotional states during the activities. This cognitive-based awareness could have favored recognition of the consequences of their own actions and helped develop listening skills and the cultivation of empathy, as found in other studies [71]. In the same line, working on concern for others' well-being has been emphasized as an important contribution to children's healthy development and socialization $[3,72,73]$.

One potential limitation of the current research could be associated with the fact that the control group continued with normal classes; however, a previous study demonstrated that children from a control group which carried out alternative activities did not show an improvement in the positive interactions between peers. Another potential limitation could be linked to the fact that we worked with one grade, since the intervention was conducted to promote positive social relationships in the group; thus, randomization was not possible. Future work carried out in other courses could provide further evidence confirming that the observed changes are not associated with a certain group but are related to the type of activities performed during this kind of intervention.

In sum, the current study shows that the practices and games conducted in the intervention enabled children to relate to others from a new perspective, improving social relationships between peers. Our findings illustrate the considerable behavioral plasticity and resilience of children. Using complex systems methodologies, the present investigation 
provides new evidence of social network plasticity, an important topic which, to our knowledge, has been little studied in children. The results indicate that positive changes in social network configuration can be promoted in educational settings. Given that these educational contexts offer a social environment that deeply affects children's development, our work highlights the beneficial effects of carrying out this kind of experience, which not only fosters prosocialness and empathic concern but also self-awareness, thus contributing to the enhancement of individual and social well-being.

\section{Conclusions}

The present study shows that a school intervention involving self-awareness and cooperative activities can enhance the diversity and quality of positive networks and reduce negative links between peers, diminishing antagonistic interactions. Since social interactions are crucial for a healthy development during childhood [63, 74-76], school interventions which improve social relationships are highly favorable. In this way, the implementation of these kinds of practices in educational settings might contribute to enhancing well-being in early life stages. The current work highlights the importance of fostering self-awareness and cooperative experiences at present, which might help increase social integration so much needed in education contexts. This investigation provides further evidence of the beneficial effects of prosocial attitudes in human wellness.

\section{Data Availability}

The data used to support the findings of this study are available from the corresponding author upon request.

\section{Conflicts of Interest}

The authors declare that there are no potential conflicts of interest with respect to the research, authorship, and/or publication of this article.

\section{Acknowledgments}

The authors acknowledge Audrey Shaw for revising the written English. This work was partially supported by Universidad Nacional del Comahue and CONICET.

\section{References}

[1] D. Byrne and G. Callaghan, Complexity Theory and the Social Sciences, Routledge, London, UK, 2014.

[2] R. Cox, "Action-selection perseveration in young children: advances of a dynamic model," 2008.

[3] L. Flook, S. B. Goldberg, L. Pinger, and R. J. Davidson, "Promoting prosocial behavior and self-regulatory skills in preschool children through a mindfulness-based kindness curriculum," Developmental Psychology, vol. 51, no. 1, pp. 44-51, 2015.

[4] H. M. Endedijk, A. H. N. Cillessen, R. F. A. Cox, H. Bekkering, and S. Hunnius, "The role of child characteristics and peer experiences in the development of peer cooperation," Social Development, vol. 24, no. 3, pp. 521-540, 2015.
[5] B. Ozawa-de Silva and B. Dodson-Lavelle, "An education of heart and mind: practical and theoretical issues in teaching cognitive-based compassion training to children," Practical Matters, vol. 1, no. 4, pp. 1-28, 2011.

[6] K. A. Schonert-Reichl, E. Oberle, M. S. Lawlor et al., "Enhancing cognitive and social-emotional development through a simple-to-administer mindfulness-based school program for elementary school children: a randomized controlled trial," Developmental Psychology, vol. 51, no. 1, pp. 52-66, 2015.

[7] F. Warneken, K. Lohse, A. P. Melis, and M. Tomasello, "Young children share the spoils after collaboration," Psychological Science, vol. 22, no. 2, pp. 267-273, 2011.

[8] J. Decety and M. Meyer, "From emotion resonance to empathic understanding: a social developmental neuroscience account," Development and Psychopathology, vol. 20, no. 4, pp. 1053-1080, 2008.

[9] T. R. A. Kral, E. Solis, J. A. Mumford et al., "Neural correlates of empathic accuracy in adolescence," Social Cognitive and Affective Neuroscience, vol. 12, no. 11, pp. 1701-1710, 2017.

[10] N. Eisenberg and N. D. Eggum, "Empathic responding: sympathy and personal distress," in The Social Neuroscience of Empathy, J. Decety and W. J. Ickes, Eds., pp. 71-83, The MIT Press, Cambridge, UK, 2009.

[11] C. D. Batson, "Empathy-induced altruistic motivation," in Prosocial motives, emotions, and behavior: The better angels of our nature, M. Mikulincer and P. R. Shaver, Eds., pp. 15-34, American Psychological Association, Washington, Wash, USA, 2010.

[12] C. D. Batson and N. Ahmad, "Empathy-induced altruism in a prisoner's dilemma II: What if the target of empathy has defected?" European Journal of Social Psychology, vol. 31, no. 1, pp. 25-36, 2001.

[13] C. D. Batson and T. Moran, "Empathy-induced altruism in a prisoner's dilemma," European Journal of Social Psychology, vol. 29, no. 7, pp. 909-924, 1999.

[14] A. C. Rumble, P. A. Van Lange, and C. D. Parks, "The benefits of empathy: when empathy may sustain cooperation in social dilemmas," European Journal of Social Psychology, vol. 40, no. 5, pp. 856-866, 2010.

[15] P. A. M. Van Lange, "Does empathy trigger only altruistic motivation? how about selflessness or justice?" Emotion, vol. 8, no. 6, pp. 766-774, 2008.

[16] W. M. Brown, N. S. Consedine, and C. Magai, "Altruism relates to health in an ethnically diverse sample of older adults," Journals of Gerontology: Series B, vol. 60, no. 3, pp. 143-152, 2005.

[17] S. Cohen and D. Janicki-Deverts, "Can we improve our physical health by altering our social networks?" Perspectives in Psychology Science, vol. 4, pp. 375-378, 2009.

[18] B. E. Kok and B. L. Fredrickson, "Upward spirals of the heart: Autonomic flexibility, as indexed by vagal tone, reciprocally and prospectively predicts positive emotions and social connectedness," Biological Psychology, vol. 85, pp. 432-436, 2010.

[19] T. W. W. Pace, L. T. Negi, D. D. Adame et al., "Effect of compassion meditation on neuroendocrine, innate immune and behavioral responses to psychosocial stress," Psychoneuroendocrinology, vol. 34, no. 1, pp. 87-98, 2009.

[20] V. Engert, B. E. Kok, I. Papassotiriou, G. P. Chrousos, and T. Singer, "Specific reduction in cortisol stress reactivity after social but not attention-based mental training," Science Advances, vol. 3, no. 10, Article ID e1700495, p. 10, 2017.

[21] S. Cohen, "Social relationships and health," American Psychologist, vol. 59, no. 8, pp. 676-684, 2004. 
[22] B. N. Uchino, "Social support and health: A review of physiological processes potentially underlying links to disease outcomes," Journal of Behavioral Medicine, vol. 29, no. 4, pp. 377-387, 2006.

[23] S. E. Taylor, "Social support: a review," in Oxford Handbook of Health Psychology, H. S. Friedman, Ed., pp. 189-214, Oxford University Press, New York, NY, USA, 2011.

[24] S. D. Pressman, S. Cohen, A. Barkin, G. E. Miller, B. S. Rabin, and J. J. Treanor, "Loneliness, social network size, and immune response to influenza vaccination in college freshmen," Health Psychology, vol. 24, no. 3, pp. 297-306, 2005.

[25] S. C. Segerstrom, "Social networks and immunosuppression during stress: Relationship conflict or energy conservation?" Brain, Behavior, and Immunity, vol. 22, no. 3, pp. 279-284, 2008.

[26] O. Kornienko, K. H. Clemans, D. Out, and D. A. Granger, "Friendship network position and salivary cortisol levels," Social Neuroscience, vol. 8, no. 4, pp. 385-396, 2013.

[27] O. Kornienko, K. H. Clemans, D. Out, and D. A. Granger, "Hormones, behavior, and social network analysis: exploring associations between cortisol, testosterone, and network structure," Hormones and Behavior, vol. 66, no. 3, pp. 534-544, 2014.

[28] O. Kornienko, D. R. Schaefer, S. Weren, G. W. Hill, and D. A. Granger, "Cortisol and testosterone associations with social network dynamics," Hormones and Behavior, vol. 80, pp. 92-102, 2016.

[29] S. Cohen and T. A. Wills, "Stress, social support, and the buffering hypothesis," Psychological Bulletin, vol. 98, no. 2, pp. 310-357, 1985.

[30] C. E. Hostinar, R. M. Sullivan, and M. R. Gunnar, "Psychobiological mechanisms underlying the social buffering of the hypothalamic-pituitary-adrenocortical axis: a review of animal models and human studies across development," Psychological Bulletin, vol. 140, no. 1, pp. 256-282, 2014.

[31] R. E. Adams, J. B. Santos, and W. M. Bukowski, "The presence of a best friend buffers the effects of negative experiences," Developmental Psychology, vol. 47, no. 6, pp. 1786-1791, 2011.

[32] E. Peters, J. M. Riksen-Walraven, A. H. N. Cillessen, and C. de Weerth, "Peer rejection and HPA activity in middle childhood: Friendship makes a difference. Child Development," Child Development, vol. 82, no. 5, pp. 1906-1920, 2011.

[33] J. R. Doom, C. M. Doyle, and M. R. Gunnar, "Social stress buffering by friends in childhood and adolescence: effects on HPA and oxytocin activity," Social Neuroscience, vol. 12, no. 1, pp. 8-21, 2016.

[34] E. Fehr and U. Fischbacher, "The nature of human altruism," Nature, vol. 425, no. 6960, pp. 785-791, 2003.

[35] M. Lozada, P. D’Adamo, and M. A. Fuentes, "Beneficial effects of human altruism," Journal of Theoretical Biology, vol. 289, no. 1, pp. 12-16, 2011.

[36] F. Warneken and M. Tomasello, "Altruistic helping in human infants and young chimpanzees," Science, vol. 311, no. 5765, pp. 1301-1303, 2006.

[37] F. Warneken and M. Tomasello, "Extrinsic rewards undermine altruistic tendencies in 20-month-olds," Developmental Psychology, vol. 44, no. 6, pp. 1785-1788, 2008.

[38] F. Warneken and M. Tomasello, "The roots of human altruism," British Journal of Psychology, vol. 100, pp. 455-471, 2009.

[39] C. Zahn-Waxler, M. Radke-Yarrow, E. Wagner, and M. Chapman, "Development of concern for others," Developmental Psychology, vol. 28, no. 1, pp. 126-136, 1992.

[40] L. B. Aknin, J. K. Hamlin, and E. W. Dunn, "Giving leads to happiness in young children," PLoS ONE, vol. 7, no. 6, 2012.
[41] J. K. Hamlin, K. Wynn, and P. Bloom, "Social evaluation by preverbal infants," Nature, vol. 450, no. 7169, pp. 557-559, 2007.

[42] J. K. Hamlin, K. Wynn, and P. Bloom, "3-month-olds show a negativity bias in their social evaluations," Developmental Science, vol. 13, no. 6, pp. 923-929, 2010.

[43] H. De Jaegher, E. Di Paolo, and S. Gallagher, "Can social interaction constitute social cognition?" Trends in Cognitive Sciences, vol. 14, no. 10, pp. 441-447, 2010.

[44] E. Di Paolo and H. De Jaegher, "The interactive brain hypothesis," Frontiers in Human Neuroscience, vol. 6, p. 163, 2012.

[45] H. De Jaegher and E. Di Paolo, "Participatory sense-making," Phenomenology and the Cognitive Sciences, vol. 6, no. 4, pp. 485507, 2007.

[46] E. Thompson and F. J. Varela, "Radical embodiment: neural dynamics and consciousness," Trends in Cognitive Sciences, vol. 5, no. 10, pp. 418-425, 2001.

[47] S. Gallagher, "Two problems of intersubjectivity," Journal of Consciousness Studies, vol. 16, no. 6-8, pp. 289-308, 2009.

[48] M. Lozada, N. Carro, P. D’Adamo, and C. Barclay, "Stress management in children: a pilot study in 7 to 9 year olds," Journal of Developmental \& Behavioral Pediatrics, vol. 35, no. 2, pp. 144-147, 2014.

[49] M. Lozada, P. D’Adamo, and N. Carro, "Plasticity of altruistic behavior in children," Journal of Moral Education, vol. 43, no. 1, pp. 75-88, 2014.

[50] A. Diamond and K. Lee, "Interventions shown to aid executive function development in children 4-12 years old," Science, vol. 333, no. 6045, pp. 959-964, 2011.

[51] T. Mendelson, M. T. Greenberg, J. K. Dariotis, L. F. Gould, B. L. Rhoades, and P. J. Leaf, "Feasibility and preliminary outcomes of a school-based mindfulness intervention for urban youth," Journal of Abnormal Child Psychology, vol. 38, no. 7, pp. 985994, 2010.

[52] E. M. S. Sibinga, C. Perry-Parrish, S.-E. Chung, S. B. Johnson, M. Smith, and J. M. Ellen, "School-based mindfulness instruction for urban male youth: a small randomized controlled trial," Preventive Medicine, vol. 57, no. 6, pp. 799-801, 2013.

[53] M. Garaigordobil, “Programa Juego 10-12 años,” Juegos cooperativos y creativos para grupos de niños de 10 a 12 años, Madrid, Pirámide, 2004.

[54] M. Garaigordobil, "Programa Juego 6-8 años," Juegos cooperativos y creativos para grupos de niños de 6 a 8 años, Madrid, Pirámide, 2005.

[55] M. Diab, R.-L. Punamäki, E. Palosaari, and S. R. Qouta, "Can psychosocial intervention improve peer and sibling relations among war-affected children? impact and mediating analyses in a randomized controlled trial," Social Development, vol. 23, no. 2, pp. 215-231, 2014.

[56] D. DeLay, L. Zhang, L. D. Hanish et al., "Peer influence on academic performance: a social network analysis of socialemotional intervention effects," Prevention Science, vol. 17, no. 8, pp. 903-913, 2016.

[57] S. D. Gest, D. W. Osgood, M. E. Feinberg, K. L. Bierman, and J. Moody, "Strengthening prevention program theories and evaluations: contributions from social network analysis," Prevention Science, vol. 12, no. 4, pp. 349-360, 2011.

[58] P. M. Gutiérrez, "El sociograma como instrumento que desvela la complejidad," Empiria. Revista de Metodología de Ciencias Sociales, vol. 2, pp. 129-152, 1999.

[59] J. L. Moreno, Fundamentos de la Sociometría, Paidós, Buenos Aires, Argentina, 1972. 
[60] V. D. Blondel, J. Guillaume, R. Lambiotte, and E. Lefebvre, "Fast unfolding of communities in large networks," Journal of Statistical Mechanics: Theory and Experiment, vol. 2008, no. 10, Article ID P10008, 2008.

[61] M. E. Newman, "Assortative mixing in networks," Physical Review Letters, vol. 89, no. 20, Article ID 208701, 2002.

[62] C. Kadushin, Understanding Social Networks: Theories, Concepts and Findings, Oxford University Press, New York, NY, USA, 2011.

[63] D. Ponzi, M. P. Muehlenbein, D. C. Geary, and M. V. Flinn, "Cortisol, salivary alpha-amylase and childrens perceptions of their social networks," Social Neuroscience, vol. 11, no. 2, pp. 164174, 2015.

[64] M. Golemiec, J. Schneider, W. T. Boyce, N. R. Bush, N. Adler, and J. D. Levine, "Layered social network analysis reveals complex relationships in kindergarteners," Frontiers in Psychology, vol. 7, article 276, 2016.

[65] J. W. Kim, B. N. Kim, J. I. Kim et al., "Social network analysis reveals the negative effects of Attention-Deficit/Hyperactivity Disorder (ADHD) symptoms on friend-based student networks," PloS ONE, vol. 10, no. 11, Article ID e0142782, pp. 10-11, 2015.

[66] S. Roerig, F. Van Wesel, S. Evers, and L. Krabbendam, "Researching children's individual empathic abilities in the context of their daily lives: the importance of mixed methods," Frontiers in Neuroscience, vol. 9, article 261, 2015.

[67] N. Eisenberg and R. A. Fabes, "Emotion regulation and the development of social competence," in Emotion and social behavior, M. S. Clark, Ed., vol. 14 of Review of personality and social psychology, pp. 119-150, Sage, Newbury Park, California, calif, USA, 1992.

[68] E. L. Garland, A. W. Hanley, P. R. Goldin, and J. J. Gross, “Testing the mindfulness-to-meaning theory: evidence for mindful positive emotion regulation from a reanalysis of longitudinal data," PLoS ONE, vol. 12, no. 12, Article ID e0187727, 2017.

[69] P. R. Goldin and J. J. Gross, "Effects of mindfulness-based stress reduction (MBSR) on emotion regulation in social anxiety disorder," Emotion, vol. 10, no. 1, pp. 83-91, 2010.

[70] M. Xu, C. Purdon, P. Seli, and D. Smilek, "Mindfulness and mind wandering: The protective effects of brief meditation in anxious individuals," Consciousness and Cognition, vol. 51, pp. 157-165, 2017.

[71] A. Böckler, L. Herrmann, F. M. Trautwein, T. Holmes, and T. Singer, "Know thy selves: Learning to understand oneself increases the ability to understand others," Journal of Cognitive Enhancement, vol. 1, no. 2, pp. 197-209, 2017.

[72] R. W. Roeser and J. S. Eccles, "Mindfulness and compassion in human development: Introduction to the special section," Developmental Psychology, vol. 51, no. 1, 2015.

[73] Z. E. Taylor, N. Eisenberg, and T. L. Spinrad, "Respiratory sinus arrhythmia, effortful control, and parenting as predictors of children's sympathy across early childhood," Developmental Psychology, vol. 51, no. 1, pp. 17-25, 2015.

[74] M. Hamer, E. Stamatakis, and G. Mishra, "Psychological distress, television viewing, and physical activity in children aged 4 to 12 years," Pediatrics, vol. 123, no. 5, pp. 1263-1268, 2009.

[75] C. Perry-Parrish, N. Copeland-Linder, L. Webb, and E. M. Sibinga, "Mindfulness-based approaches for children and youth," Current Problems in Pediatric and Adolescent Health Care, vol. 46, no. 6, pp. 172-178, 2016.
[76] D. Prentice, "Mobilizing and weakening peer influence as mechanisms for changing behavior: implications for alcohol intervention programs," in Peer Influence Processes among Youth, M. Prinstein and K. Dodge, Eds., pp. 161-180, Guilford Press, New York, NY, USA, 2008. 


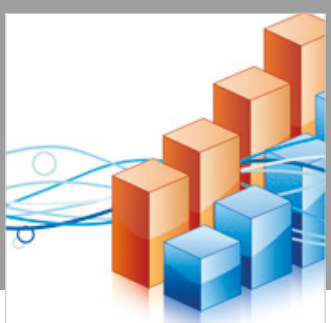

Advances in

Operations Research

\section{-n-m}
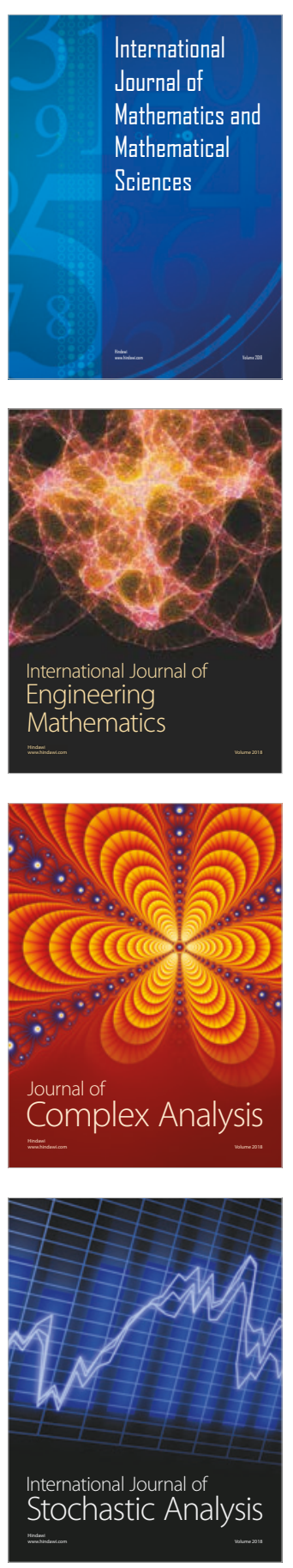
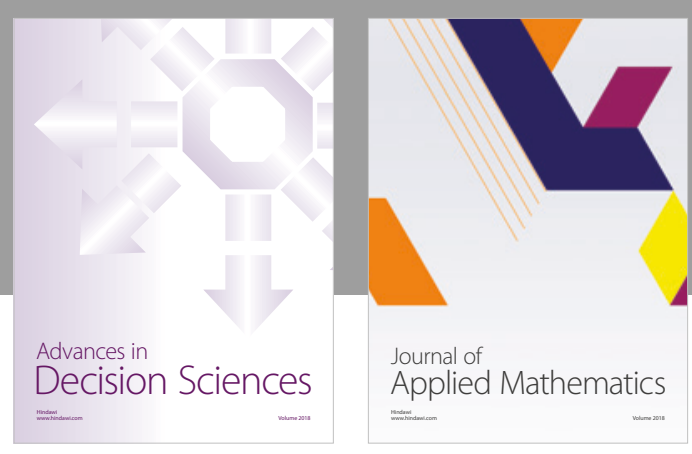

Journal of

Applied Mathematics
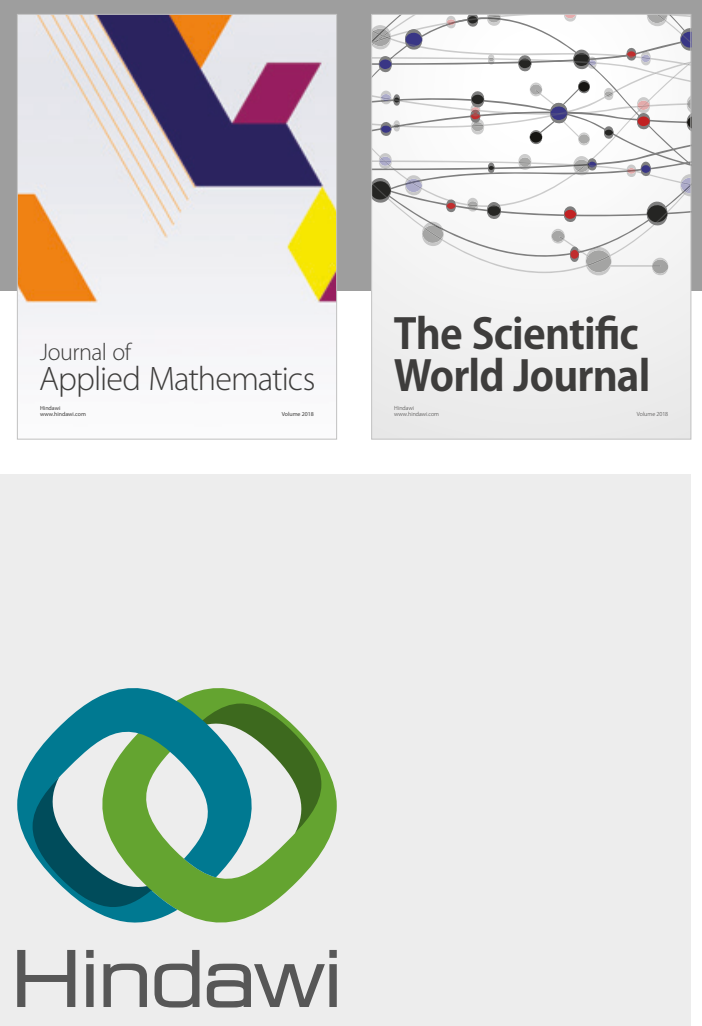

Submit your manuscripts at

www.hindawi.com

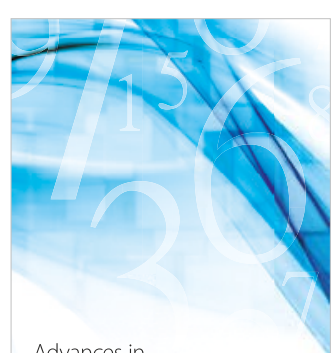

Advances in
Numerical Analysis
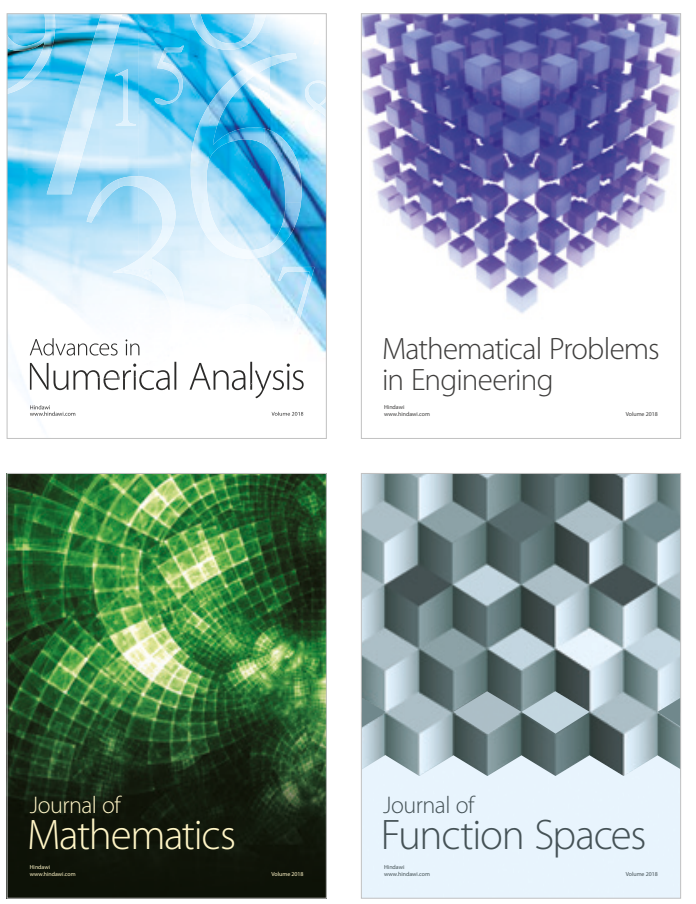

Mathematical Problems in Engineering

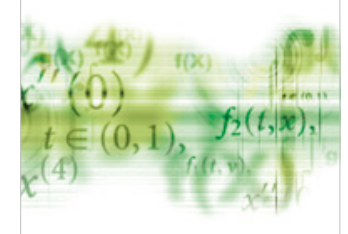

International Journal of

Differential Equations

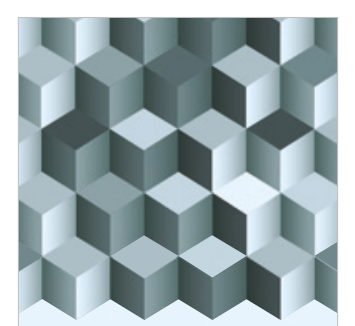

Journal of

Function Spaces
The Scientific

World Journal

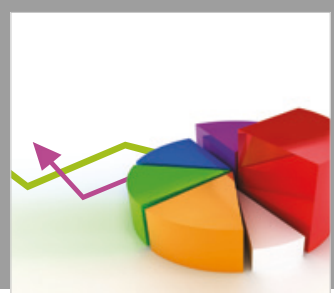

Journal of

Probability and Statistics
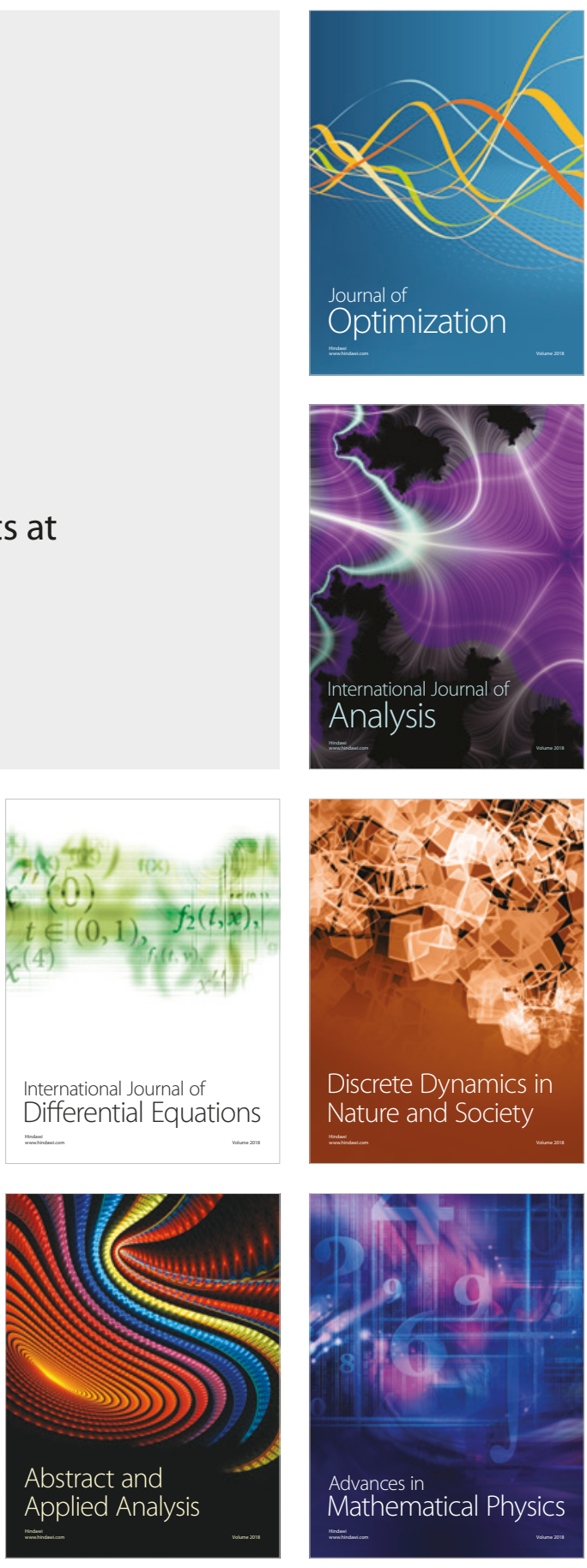